\title{
Effects of an Elastic Resistance Band Intervention in Adolescent Handball Players
}

\section{(c) (i) (우 $\ominus$}

\author{
Authors \\ Julian Bauer ${ }^{\mathbb{D}}$, Gerrit Schwiertz, Thomas Muehlbauer
}

\author{
Affiliation \\ Division of Movement and Training Sciences, University of \\ Duisburg-Essen, Essen, Germany
}

Key words

training sciences, elastic resistance band exercises, handball training

$\begin{array}{ll}\text { received } & 23.12 .2020 \\ \text { revised } & 05.05 .2021 \\ \text { accepted } & 11.05 .2021\end{array}$

\section{Bibliography}

Sports Medicine International Open 2021; 5: E65-E72

DOI 10.1055/a-1541-2916

ISSN 2367-1890

2021. The Author(s).

This is an open access article published by Thieme under the terms of the Creative Commons Attribution-NonDerivative-NonCommercial-License, permitting copying and reproduction so long as the original work is given appropriate credit. Contents may not be used for commercial purposes, or adapted, remixed, transformed or built upon. (https://creativecommons. org/licenses/by-nc-nd/4.0/).

Georg Thieme Verlag, Rüdigerstraße 14,

70469 Stuttgart, Germany

\section{Correspondence}

Dr. Julian Bauer

Division of Movement and Training Sciences

University of Duisburg-Essen

Gladbecker Str. 182

45141 Essen

Germany

Tel. : +49201183 7325,

julian.bauer@uni-due.de

\section{ABSTRACT}

The objective was to investigate the effects of a 9-week elastic resistance band training within the regular handball training sessions compared to regular handball training only. Participants were randomly assigned to an intervention (INT: $n=16$; age: $17.0 \pm 0.7$ years) or a control (CON: $n=16$; age: $16.9 \pm$ 0.9 years) group. The INT-group performed elastic resistance band exercises (3/week) for 20-30 minutes while the CONgroup conducted regular handball training only. Pre- and posttraining assessments included measures of strength endurance (Closed Kinetic Chain Upper Extremity Stability Test [CKCUEST]), maximal isometric strength (MIS), and throwing velocity. Significant main effects of Test (i.e. pre- to post-training enhancements) were detected for the CKCUEST ( $p<0.001$, $\left.0.54 \leq \eta_{\mathrm{p}}{ }^{2} \leq 0.57\right)$ and throwing velocity $\left(\mathrm{p}=0.001, \eta_{\mathrm{p}}{ }^{2}=\right.$ 0.34 ). We found a significant (throwing velocity: $p=0.004$, $\eta_{p}{ }^{2}=0.25$ ) and a tendency toward (MIS of the internal rotators, non-throwing arm: $p=0.068, \eta_{p}^{2}=0.12$ ) a significant Test $x$ Group interaction, both in favour of the INT-group. A 9-week strengthening program using elastic resistance bands combined with regular handball training is effective to improve upper extremity strength endurance, throwing velocity, and MIS of the internal rotators of the non-throwing arm.

\section{Introduction}

Handball is a dynamic Olympic full-contact sport and one of the most popular sports in Europe [1]. Repetitive overhead throwing actions are an integral part of the game [2]. The importance of throwing on individual as well as team success has been assessed by original studies $[3,4]$ and reviews $[5,6]$. More precisely, adoles- cent handball players are reported to perform an average of 100.9 passes and 10.1 shots during a $2 \times 25$-minute game [7].

Based on this handball-specific load, training programs have to be developed. Elastic resistance bands are simple training means that can be used within the training time and have the potential to improve functional and in-game performance of athletes [8]. The development and effectiveness testing of such elastic resistance 
band interventions give insights on the prescription and training load on an individual basis. In this regard, Mascarin et al. [9] were able to report significant gains in throwing velocity and isokinetic shoulder internal rotator strength after six weeks of a triweekly elastic resistance band training in adolescent female handball players ( $n=21$, age: $15.3 \pm 1.1$ years) compared to a control group ( $n=18$, age: $15.0 \pm 0.8$ years). In a similar study, the same authors [10] were able to report positive effects on the ratio of the shoulder internal and external rotators following six weeks of elastic resistance band training ( 3 times per week) in adolescent female handball players (dominant upper limb group: $n=8$, age: $15.3 \pm 0.9$ years and non-dominant upper limb group: $n=5$, age: $15.2 \pm 0.5$ years) compared to the dominant upper limb control group $(n=7$, age: $15.9 \pm 1.2$ years) and the non-dominant upper limb control group ( $n=5$, age: $15.4 \pm 0.9$ years). The aforementioned studies assessed young female handball players, and therefore the transferability of these results to young male players remains unclear owing to differences in growth and maturation [11]. More specifically, studies have shown male players to be taller, heavier, and stronger [12-14]. These anthropometric differences may account for better physical (e. g., jump height) and athletic (e. g., throwing velocity) performances in male compared to female handball players [15-17]. Consequently, training-related changes may differ between sexes. This could be either in favour of males owing to their more mature muscular system [18] or in favour of females owing to their higher adaptive reserve [19]. Besides these aspects, the studies of Mascarin et al. [9, 10] displayed the methodical weakness that the elastic resistance band exercises were executed in addition to regular handball training and thus increased the overall training load in the intervention group compared to the control groups of these studies, leaving unclear whether the improvements were a result of the specific elastic resistance band training or the increased overall training load.

The aim of this study was to investigate the effects of a triweekly 9 -week shoulder strengthening program using elastic resistance bands during handball training compared to regular handball training only on measures of physical (i.e. strength endurance and maximal strength) and athletic (i. e. throwing velocity) performance in male adolescent handball players. Our hypothesis was that both groups will improve their performances with superior effects for the elastic resistance band training group.

\section{Methods}

\section{Participants}

Out of 23 junior male handball teams that were chosen to be eligible based on their affiliation with the same regional playing class and age category, the first two teams that responded to be willing to participate were assigned to the control (CON) or the intervention (INT) group using the Research Randomizer software (www. randomizer.org) ( $\triangleright$ Fig. 1). The INT group consisted of 17 subjects. As one subject did not finish the intervention owing to personal reasons, 16 subjects were included in the analysis. In contrast, the CON group initially included 18 subjects. However, two subjects did not participate in the pretesting, therefore, 16 subjects were included in the analysis. There were no significant differences between the two groups ( $\triangleright$ Table 1 ).

Prior to the study, all players and their coaches were informed about the study goals. After agreeing to take part, all players gave written consent and the subjects who were under the age of 18 years additionally handed in an informed consent from their parents or legal guardians. Exclusion criteria were any injury that hindered the subjects from training or games in the two weeks before testing. Prior to each testing session, the participants were asked if they suffered from any condition, pain or injury that could affect their performance in the tests. The study was carried out according to the Declaration of Helsinki, the Ethical Standards in Sport and Exercise Research: 2020 Update [20] and the Human Ethics Committee at the University of Duisburg-Essen, Faculty of Social Sciences approved the study protocol (TM_23.03.2020).

\section{Training program}

Both the participants of the INT and CON group performed their regular handball routine (3 times per week, 90 minutes per session). The participants of the INT group executed a 9-week shoulder strengthening program (3 times per week; 20-30 minutes per session) within their regular 90-minute handball training session. All training sessions were carried out at the beginning of the competition period and were conducted according to the training methodology framework [21] of the German Handball Association, which stipulates the training content in this age category to consist of $30 \%$ of athletic exercises, $20 \%$ of fast break exercises, $10 \%$ of team level offensive and defensive training, $20 \%$ of cooperative offensive and defensive training as well as $20 \%$ of individual offensive and defensive training. The $\mathrm{CON}$ group also conducted the first 20-30 minutes of their handball-specific training following the guidelines of the German Handball Association [21], which consisted of throwing exercises whereas the INT group executed the specific shoulder intervention resulting in the same temporary training load of 90 minutes for both groups. A TheraBand (The Hygenic Corporation, Akron, $\mathrm{OH}$, USA) resistance level green (i. e. heavy resistance; $4.6 \mathrm{lbs}$ at $100 \%$ elongation) was used for every exercise. Training progression was assured through exercise variations and increase of repetitions ( $>$ Fig. 2). Before the beginning of the training sessions, the coaches were given pictures with the description of the exercises. All athletes received their own resistance band, and substitute resistance bands were present in all training sessions. One member of the testing staff demonstrated the exercises prior to the first execution by the players. The participants were instructed to start the movement in $100 \%$ elongation of the bands. To individualise the training intensity, the players were instructed to stretch the band in accordance to their strength level. All exercises were executed within the regular handball training sessions in a non-fatigued but warmed-up condition. The intervention program consisted of three sets of six exercises, i. e. the six movement directions of the shoulder: anteversion, retroversion, internal rotation, external rotation, abduction, and adduction with three series of 8 repetitions in week 1 , week 4 , and week 7 ; three series of 10 repetitions in week 2 , week 5 , and week 8 ; and three series of 12 repetitions in week 3 , week 6 , and week 9 . These same six exercises were executed for the first three weeks and replaced by six new exercises in week 4-6; from week 7-9 the final six new exer- 




- Fig. 1 Flowchart of the progress through the phases of the study according to the CONSORT statements 2010.

- Table 1 Characteristics of the study participants $(N=32)$ by group.

\begin{tabular}{|l|l|l|l|}
\hline Characteristic & $\begin{array}{l}\text { INT group } \\
(\mathbf{n = 1 6 )}\end{array}$ & $\begin{array}{l}\text { CON group } \\
(\mathbf{n}=\mathbf{1 6})\end{array}$ & $\boldsymbol{p}$-value \\
\hline Age [yrs] & $17.0 \pm 0.7$ & $16.9 \pm 0.9$ & 0.666 \\
\hline $\begin{array}{l}\text { Maturity offset }{ }^{*} \\
\text { [years from PHV] }\end{array}$ & $3.08 \pm 0.74$ & $3.06 \pm 0.69$ & 0.917 \\
\hline Body mass [kg] & $80.5 \pm 12.9$ & $74.5 \pm 14.8$ & 0.228 \\
\hline Body height [cm] & $180.4 \pm 7.6$ & $181.4 \pm 6.6$ & 0.693 \\
\hline BMI [kg/m²] & $24.7 \pm 3.5$ & $22.5 \pm 3.3$ & 0.073 \\
\hline Arm dominance [l/r] & $1 / 15$ & $2 / 14$ & - \\
\hline Throwing arm [l/r] & $1 / 15$ & $1 / 15$ & - \\
\hline $\begin{array}{l}\text { Training experience } \\
\text { [yrs] }\end{array}$ & $9.3 \pm 3.1$ & $7.9 \pm 2.9$ & 0.221 \\
\hline $\begin{array}{l}\text { Data are group mean values } \pm \text { standard deviations. }{ }^{*} \text { Maturity offset } \\
\text { was calculated by using the formula provided by Moore et al. [36]. }\end{array}$ \\
$\begin{array}{l}\text { BMI= body mass index; CON = control group; INT=intervention } \\
\text { group; I= left; } r=\text { right; PHV= peak height velocity. }\end{array}$ \\
\hline
\end{tabular}

cises were implemented ( $\triangleright$ Fig. 2 ). In order to prevent training monotony over the 9 weeks of training while still assuring training progression, varying exercises with steady resistance but increasing repetitions were used. Weekly phone calls between the examiner of the study and the coaches were conducted to keep the training intensity on a similar level. The participants were asked to perform all exercises in a steady and uninterrupted movement during both the concentric and the eccentric phase. Precision in execution was assured through constant observation by the coaches.

\section{Testing procedures}

\section{Assessment of Anthropometric Variables}

Prior to the intervention, the anthropometric variables body height and body mass were assessed. Body height was registered with a seca 217 (seca, Basel, Switzerland) linear measurement scale without shoes to the nearest $0.1 \mathrm{~cm}$. Body mass was assessed without shoes, in light sportswear that was subsequently worn during the testing, with an electronic seca 803 scale to the nearest $100 \mathrm{~g}$. The body mass index (BMI) was calculated as body mass divided by body height squared $\left(\mathrm{kg} / \mathrm{m}^{2}\right)$. Besides these variables, the subjects were asked for how many years they had been training in and playing handball (i. e. training experience) and what their dominant as well as throwing arm is.

\section{Assessment of Strength Endurance}

The closed kinetic chain upper extremity stability test (CKCUEST) as described by Tucci et al. [22] was used to assess muscular endurance with an electronic clock to gauge the time. The CKCUEST is a 


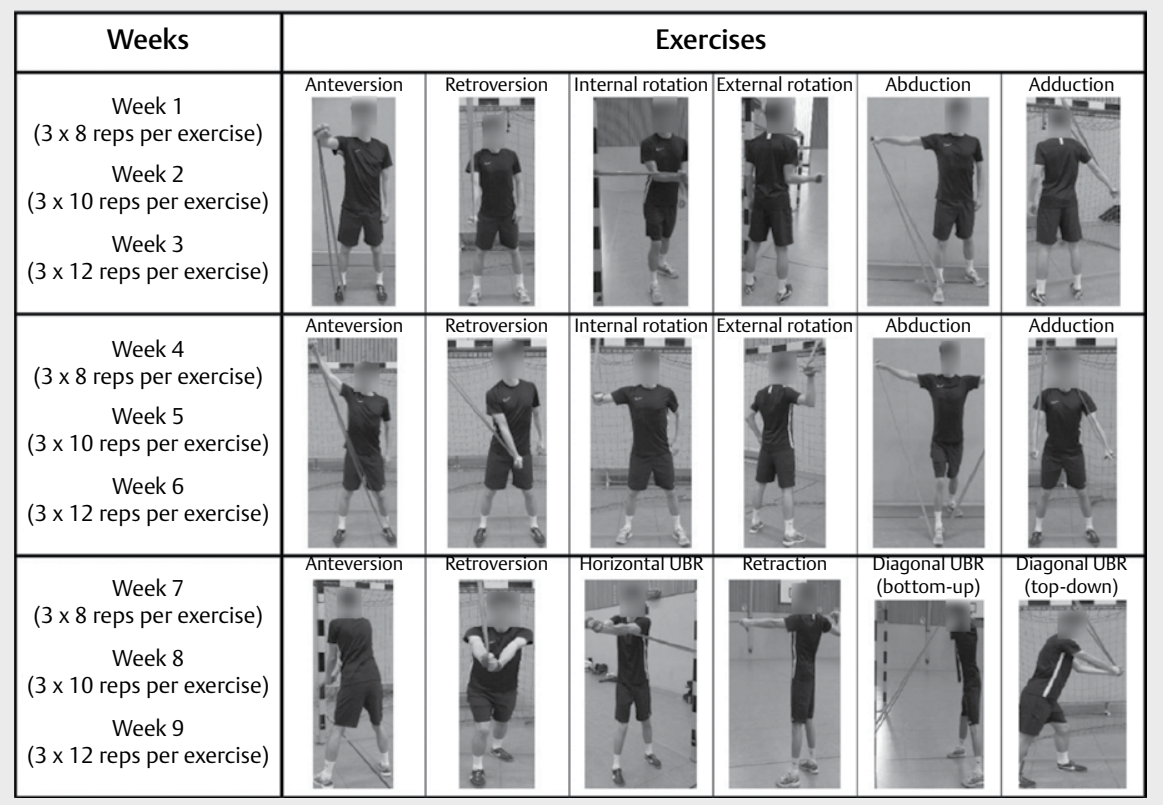

Fig. 2 Description of the shoulder strengthening program using elastic resistance bands. UBR= upper body rotation.

field test for measuring muscular endurance of the shoulder girdle. Based on this, conclusions about the resistance against fatigue can be drawn. Muscular fatigue develops during handball training sessions and games and is associated with performance impairments [23] and an increased risk of injuries [24]. During the CKCUEST, the participants had to assume a push-up position with hands placed 36 inches (approx. $91.44 \mathrm{~cm}$ ) apart, flat back, and shoulders perpendicular to the wrists. As soon as the test started, the subjects had to alternately touch the supporting hand with the nonsupporting hand as fast as possible for the duration of $15 \mathrm{~s}$. A total of three trials was performed separated by 45 -s rest periods. Between trials, the participants could rest in a position chosen by themselves to be comfortable. Each trial started and ended with an acoustic beep. Prior to each trial, a 3-s verbal countdown was given. The number of touches was noted down for each trial with the best one (i. e. highest number of touches) used for further analysis. Further, the relative CKCUEST score was calculated as the mean number of touches divided by subjects' body height (cm). Lastly, CKCUEST power was computed by multiplying the average number of touches by $68 \%$ of subjects' body mass $(\mathrm{kg})$ divided by 15 $[22,25]$. The CKCUEST has been shown to have moderate to excellent reliability for adolescents [26]. In addition, intraclass correlation coefficients (ICC) were calculated for the CKCUEST using the pretest data of both groups. The obtained values were "excellent" and ranged from ICC $=0.84-0.97$ for the different trial comparisons (i. e. $1^{\text {st }}$ vs. $2^{\text {nd }}$ vs. $3^{\text {rd }}$ trial).

\section{Assessment of Maximal Isometric Strength}

Maximal isometric strength (MIS) of the internal rotators was assessed to the nearest $0.01 \mathrm{Nm}$ using a Kistler 9321B (Kistler, Winterthur, Switzerland) force transducer and a custom-built dy- namometer. While sitting, the subjects had to flex the elbow to $90^{\circ}$ with the shoulder being abducted to $90^{\circ}$. The rotational axis of the dynamometer was positioned at the participants' shoulder joint with the handlebar being adjusted to their respective forearm length [27]. During testing, the participants were asked to sit upright and grasp the handlebar tightly with their forearm positioned in the dynamometer. Additionally, the subjects were given a counterbalance weight $(1.25 \mathrm{~kg})$ to hold in the opposite hand and were strapped to the chair. The individual adjustment values were noted down and used again for the posttest. All subjects were asked to maximally rotate their shoulder internally for approximately three seconds as soon as the experimenter verbally announced it. After a rest period of $30 \mathrm{~s}$, the left arm was tested again being followed by two trials of the right arm after the subject changed the direction of the seat position. The values of each trial were noted down manually on a sheet and electronically on a laptop with custom LabVIEW software (version 2016; National Instruments, Austin, TX, USA). A moving average filter with a window width set to $500 \mathrm{~ms}$ was used to smooth the force signal, and the best trial (i. e. highest value) of each side was used for further analysis.

\section{Assessment of Athletic Performance}

A target net (SG $500 \mathrm{~L}$; size: $3 \mathrm{~m} \times 2 \mathrm{~m}$ ) was attached to a handball goal in the training venue of the clubs. Within this target net, there was a hole of a $1 \mathrm{~m} \times 1 \mathrm{~m}$, into which the players had to throw. A "Stalker Pro" radar gun (Applied Concepts Inc., Richardson, TX, USA) was placed behind the goal net at a height of $1.20 \mathrm{~m}$ facing in the direction of the hole of the goal net to secure the Doppler effect. The radar gun measures velocities from 0 to $480 \mathrm{~km} / \mathrm{h}$ with an accuracy of $0.16 \mathrm{~km} / \mathrm{h}$ in a 0.01 -s time interval. The working frequency of the "Stalker Pro" is reported to be $35.1 \mathrm{GHz}$ with a low 
disturbance threshold [28]. One of the testers was positioned behind the goal net to assess the throwing velocity, reporting the value to be noted down on the scoring sheet of each athlete by the second tester. The subjects had to place their contralateral leg at the 7-m line while holding the ball with their throwing arm. A bench was put alongside on the 7-m line and the player could touch it with the contralateral foot but not fall over the bench during or after throwing. All players used the same standard ball size 3. All throws were executed as standing throws with no run-up, taking into account the guidelines of the German Handball Federation [21]. The fastest throwing velocity was noted down out of three consecutive trials immediately following each other. Only the throwing arm was tested. In a recent study, Rios et al. [29] reported this kind of throwing execution to be highly reliable $($ ICC $=0.89)$.

\section{Statistical analyses}

Descriptive data are reported in terms of group mean values and standard deviations. A univariate analysis of variance (ANOVA) was performed to test for significant discrepancies in pretest values between the two groups. Thereafter, a 2-way mixed ANOVA was performed using "Test: Pre, Post" (within-subject factor) and "Group: INT, CON" (between-subject factor) as independent variables. The assessed performance measures (i. e. strength endurance, maximal isometric strength, throwing velocity) were used as dependent variables. If a significant $(p \leq 0.05)$ or a tendency toward a significant $(0.05<p<0.10)$ Test $\times$ Group interaction occurred, differences between pretest and posttest values were analysed for each group separately with the help of paired $t$-tests. Furthermore, the partial eta-squared $\left(\eta_{p}{ }^{2}\right)$ was used as an effect size measure and classified as small $\left(0.02 \leq \eta_{p}{ }^{2} \leq 0.12\right)$, medium $\left(0.13 \leq \eta_{p}{ }^{2} \leq 0.25\right)$, and large $\left(\eta_{p}^{2} \geq 0.26\right)$. All statistical analyses were performed using Statistical Package for Social Sciences version 27.0 (IBM Corp., Armonk, NY, USA).

\section{Results}

- Table 2 displays statistics for all analysed variables. In general, there were no statistically significant differences in pretest values between the two groups.

\section{Strength endurance}

Irrespective of the used measure, the analysis detected significant main effects of Test $\left(34.543 \leq F_{1,30} \leq 40.439\right.$, all $p<0.001$, $\left.0.54 \leq \eta_{\mathrm{p}}{ }^{2} \leq 0.57\right)$ and Group $\left(5.325 \leq F_{1,30} \leq 6.714,0.015 \leq p \leq 0.028\right.$, $\left.0.15 \leq \eta_{p}{ }^{2} \leq 0.18\right)$. The interaction effects of Test $\times$ Group were not significant.

\section{Maximal isometric strength}

For the MIS of the internal rotators of the non-throwing but not of the throwing arm, we found a tendency toward a significant Test $\times$ Group interaction $\left(F_{1,30}=3.616, p=0.068, \eta_{p}{ }^{2}=0.12\right)$ ( $\triangleright$ Table 2). The post-hoc analysis yielded that the participants in the INT group significantly increased their strength values over the training period $\left(\Delta+12.6 \%, p=0.05, \eta_{p}^{2}=0.03\right)$ whereas the participants in the CON group showed no significant changes $(\Delta-0.9 \%$, $\left.p=0.82, \eta_{p}{ }^{2}=0.01\right)(\triangleright$ Fig. 3A). The main effect of Test showed a tendency toward a significance for the non-throwing $\left(F_{1,30}=3.392\right.$,

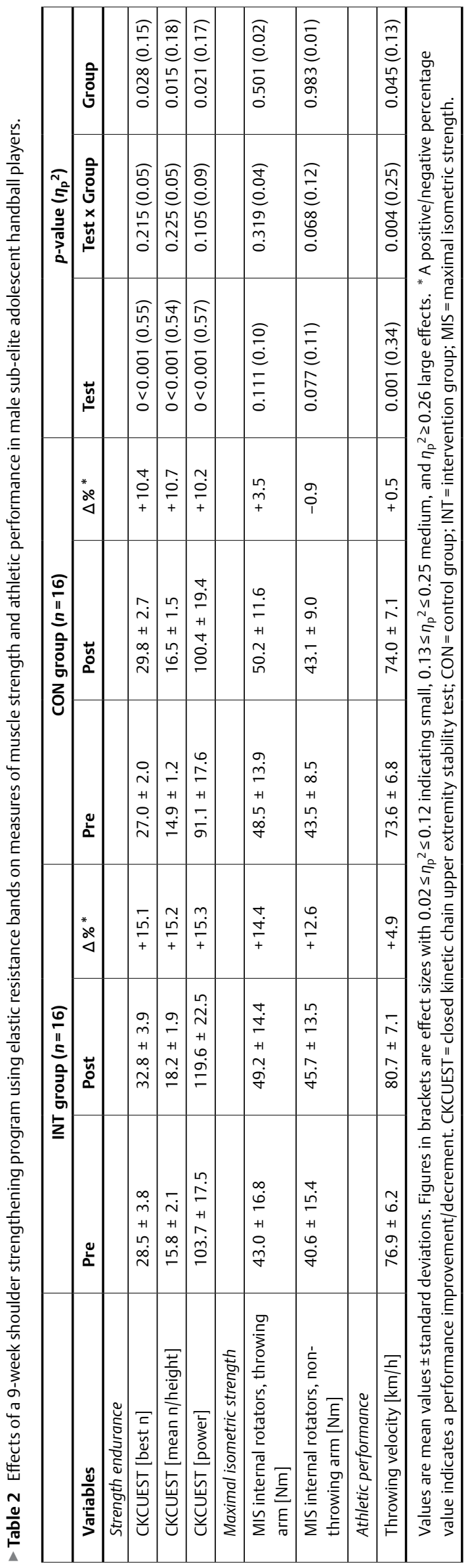



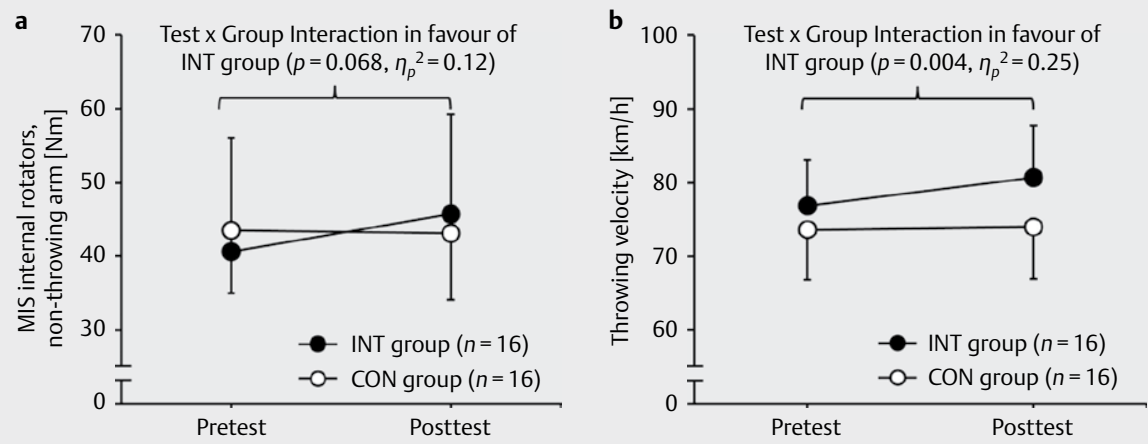

- Fig. 3 Maximal isometric strength (MIS) of the internal rotators, non-throwing arm (a) and throwing velocity (b) comparing the intervention (INT) with the control (CON) group.

$p=0.077, \eta_{p}^{2}=0.11$ ) but not for the throwing arm. Irrespective of arm, the main effect of Group was not significant.

\section{Athletic performance}

For the throwing velocity, our analyses indicated significant main effects of Test $\left(F_{1,30}=14.979, p=0.001, \eta_{p}{ }^{2}=0.34\right)$ and Group $\left(F_{1,30}=4.405, p=0.045, \eta_{\mathrm{p}}^{2}=0.13\right)$ as well as a significant Test $\times$ Group interaction $\left(F_{1,30}=9.508, p=0.004, \eta_{p}{ }^{2}=0.25\right)$ ( Table 2). Post-hoc analyses revealed significant enhancements over the course of training in the INT group $(\Delta+4.9 \%, p<0.001$, $\left.\eta_{p}{ }^{2}=0.07\right)$ but not in the CON group $\left(\Delta+0.5 \%, p=0.588, \eta_{p}{ }^{2}=0.01\right)$ (- Fig. 3B).

\section{Discussion}

The aim of the study was to investigate the effects of a 9-week shoulder-strength resistance training program using elastic bands on strength endurance (CKCUEST) of the upper extremities, MIS of the internal rotators, and throwing velocity in male sub-elite adolescent handball players. The main results can be summarized as follows. In both groups, strength endurance, MIS of the internal rotators for the non-throwing arm, and throwing velocity improved over the training period and the latter two were more enhanced in the INT- compared to the CON group.

\section{Effects on muscle strength}

We expected performance increases in both groups, but with superior effects for the INT group. In terms of strength endurance, we are only able to partly confirm our hypothesis because both groups enhanced their performance in the CKCUEST to a similar extent. This finding is partly in line with Mascarin et al. [9] who reported increased isokinetic internal strength in the shoulder muscles in the INT group but not in the CON group following six weeks of elastic band resistance training. Possibly, the CON group in the present study also improved owing to the strength-related throwing and passing exercises that were executed whereas the INT group executed the shoulder exercises. In contrast to regular handball training only, the specific elastic resistance band exercises within the 90-minute training sessions may be responsible for the some- what higher but not statistically significant different improvements in the INT group. The elastic resistance band exercises may have an improving effect, however, may not be a stimulus specific enough for a closed kinetic chain test which demands the interplay of different muscles to lead to significantly different effects. Both groups improved, possibly also due to the accompanying regular handball training. The scores found in the present samples (INT group: 2933 touches; CON group: 27-30 touches) were higher than the ones reported in the study by Lagniaux et al. [30], who also assessed adolescent handball players (26.7 \pm 3.6 touches). The differences in number of touches in our study compared to the study by Lagniaux et al. [30] may be explained by the fact that although in both studies adolescents were investigated, our cohort was exclusively composed of male players whereas the cohort of Lagniaux et al. [30] consisted of male and female players. It is well documented that female players possess lower muscle strength than their male counterparts [12]. This will lead to a reduced number of touches in the CKCUEST and may explain the differences between our study and the one by Lagniaux et al. [30]. The higher scores in our sample show that the players already had a good training level prior to the intervention. The benefit from the training program may be an additional indicator for its efficiency especially because the adaptive reserve in the present sample seems to be rather low owing to the high CKCUEST baseline values.

Regarding MIS, we also partly confirmed our initial hypothesis because performance for the non-throwing but not for the throwing arm was enhanced in both groups but in favour of the INT group (see post-hoc analysis). This result is again partially in concordance with the work of Mascarin et al. [9], who reported improved internal rotation strength of the throwing arm but did not test the nonthrowing arm following elastic resistance band exercises. It could be assumed that for the participants in the present study the adaptive reserve to the training stimulus is higher in the non-throwing than in the throwing shoulder. Due to the high number of throws and passes executed with the throwing arm during regular handball training, the internal rotation that resembles the throwing movement already has higher baseline values than the internal rotation of the non-throwing shoulder in both groups ( $\triangleright$ Table 2 ). This finding of higher baseline values of internal rotation strength 
in the throwing compared to the non-throwing shoulder was also reported by Raeder et al. [31] and Cools et al. [32].

In sum, the combination of a shoulder strength resistance training program using elastic bands and regular handball training can be recommended compared to regular handball training only to increase measures of upper extremity strength endurance and MIS strength of the internal rotators of the non-throwing arm in subelite male adolescent handball players. This combination gives coaches and players a cheap and feasible opportunity to improve upper extremity muscle strength for adolescent handball players within their regular training sessions.

\section{Effects on athletic performance}

The hypothesis that both groups will improve their athletic performance and that the INT group will show larger enhancements as compared to the CON group was confirmed. The throwing velocities reported in the INT group (pretest: $76.9 \pm 6.2 \mathrm{~km} / \mathrm{h}$; posttest: $80.7 \pm 7.1 \mathrm{~km} / \mathrm{h}$ ) are in accordance with different studies [33, 34] that reported throwing velocities of $72-86 \mathrm{~km} / \mathrm{h}$ in male adolescent players. Contrary to our results, Mascarin et al. [9] reported that elastic resistance band training improved both maximum internal rotation strength and throwing velocity in handball players. The training-related improvements in throwing velocity of our study, however, may lead to higher in game performance [5, 6]. Consequently, conducting the combined training of the INT group using elastic resistance band exercises together with regular handball training is recommended over single-mode handball training to increase active throwing velocity in sub-elite adolescent handball players.

\section{Limitations}

As a limitation, external shoulder rotation strength was not assessed. At the time of throwing, the external rotators function as antagonistic muscles in the acceleration phase and play a decisive role in the last phase of the action, which can influence the final output. Thus, future studies should investigate the effects of elastic resistance-band shoulder-strengthening exercises on both external and internal rotator strength. Further, the assessment of both strength measures also makes it possible to look at the external/internal rotator strength ratio [35], which is a significant indicator of an increased risk of shoulder overuse injury [2]. In addition, our findings are limited to the examined age group (i. e. adolescent handball players). Therefore, we cannot comment on trainingrelated adaptations to other groups of younger (junior athletes) or older (senior athletes) handball players. Further, the underlying adaptations of the observed improvements in upper-extremity muscle strength and athletic performance remain unclear, because our methodological approach was limited to behavioural outcome measures and should therefore be investigated in future studies.

\section{Conclusions}

We investigated the effects of a 9-week elastic resistance-band shoulder-strengthening program on measures of upper-extremity muscle strength and athletic performance in male sub-elite adolescent handball players. Our data suggest that both regular handball training only (CON group) and in combination with elastic resistance band exercis- es (INT group) are effective in improving throwing velocity, upper extremity strength endurance, and MIS of the internal rotators of the non-throwing but not the throwing arm. Further, our post-hoc analyses indicate superior improvements in favour of the INT group with respect to throwing velocity and MIS of the internal rotators. Thus, coaches can use this easy to administer resistance band intervention as an adjunct to the regular handball routine when the goal is to enhance ball speed and maximal shoulder strength in particular.

\section{Availability of Data and Materials}

The data generated and analysed during the present study are not publicly available owing to ethical restrictions but are available from the corresponding author upon reasonable request.

\section{Authors' Contributions}

JB and TM designed the research question. JB planned and supervised the testings. JB and GS conducted the testings and data collection. TM and JB analysed the data. JB wrote the main part of the manuscript. TM and GS reviewed the manuscript. All authors approved the final manuscript.

\section{Ethics Approval and Consent to Participate}

Ethical permission was given by the Human Ethics Committee at the University of Duisburg-Essen, Faculty of Educational Sciences. Participants' assent and parents' written informed consent were obtained prior to the start of the study.

\section{Funding}

We acknowledge support by the Open Access Publication Fund of the University of Duisburg-Essen. The funding body is independent of the design of the study and collection, analysis, and interpretation of data and in writing the manuscript.

\section{Conflict of Interest}

The authors declare that they have no Conflict of Interest.

\section{References}

[1] Achenbach L, Luig P. Epidemiologie und Verletzungsprävention im Handball. Sportverletz Sportsc 2020; 34: 129-135. doi:10.1055/ a-1209-4666

[2] Achenbach L, Laver L, Walter S et al. Decreased external rotation strength is a risk factor for overuse shoulder injury in youth elite handball athletes. Knee Surg Sports Traumatol Arthrosc 2020; 28 : 1202-1211. doi:10.1007/s00167-019-05493-4

[3] Andrade M, de Carvalho Koffes F, Benedito-Silva A et al. Effect of fatigue caused by a simulated handball game on ball throwing velocity, shoulder muscle strength and balance ratio: a prospective study. BMC Sports Sci Med Rehabil 2016; 8: 13. doi:10.1186/ s13102-016-0038-9 
[4] Hermassi S, Delank K, Fieseler G et al. Relationships between Olympic weightlifting exercises, peak power of the upper and lower limb, muscle volume and throwing ball velocity in elite male handball players. Sportverletz Sportsc 2018; 33: 104-112. doi:10.1055/a-0625-8705

[5] Skejø SD, Møller M, Bencke J et al. Shoulder kinematics and kinetics of team handball throwing: a scoping review. Hum Mov Sci 2019; 64: 203-212. doi:10.1016/j.humov.2019.02.006

[6] Vila $\mathrm{H}$, Ferragut $\mathrm{C}$. Throwing speed in team handball: A systematic review. Int J Perform Anal Spor 2019; 19: 724-736. doi:10.1080/2474 8668.2019.1649344

[7] Chelly MS, Hermassi S, Aouadi R et al. Match analysis of elite adolescent team handball players. J Strength Cond Res 2011; 25: 2410-2417. doi:10.1519/JSC.0b013e3182030e43

[8] Aloui G, Hammami M, Fathloun M et al. Effects of an 8-week in-season elastic band training program on explosive muscle performance, change of direction, and repeated changes of direction in the lower limbs of junior male handball players. J Strength Cond Res 2018; 33 : 1804-1815. doi:10.1519/JSC.0000000000002786

[9] Mascarin NC, De Lira CAB, Vancini RL et al. Strength training using elastic bands: Improvement of muscle power and throwing performance in young female handball players. J Sport Rehabil 2017; 26: 245-252. doi:10.1123/jsr.2015-0153

[10] Mascarin NC, De Lira CAB, Vancini RL et al. The effects of preventive rubber band training on shoulder joint imbalance and throwing performance in handball players: a randomized and prospective study. J Bodyw Mov Ther 2017; 21: 1017-1023. doi:10.1016/j.jbmt.2017.01.003

[11] Malina R, Bouchard C, Bar-Or O. Growth, Maturation, and Physical Activity. Champaign, III: Human Kinetics;; 2004. doi:10.5040/9781492596837

[12] Ingebrigtsen J, Jeffreys I, Rodahl S. Physical characteristics and abilities of junior elite male and female handball players. J Strength Cond Res 2013; 27: 302-309. doi:10.1519/JSC.0b013e318254899f

[13] Torres-Luque G, Calahorro-Canada F, Nikolaidis PT. Age-related differences in physical and physiological characteristics in male handball players. Arch Med Deporte 2016; 33: 318-324

[14] Wagner $\mathrm{H}$, Fuchs $\mathrm{P}$, Fusco $\mathrm{A}$ et al. Physical performance in elite male and female team-handball players. Int J Sport Physiol Perform 2019; 14: 60-67. doi:10.1123/ijspp.2018-0014

[15] Ortega-Becerra M, Pareja-Blanco F, jimenez-Reyes P et al. Determinant factors of physical performance and specific throwing in handball players of different ages. J Strength Cond Res 2018; 32: 1778-1786. doi:10.1519/JSC.0000000000002050

[16] Gorostiaga EM, Granados C, Ibanez J et al. Differences in physical fitness and throwing velocity among elite and amateur male handball players. Int J Sports Med 2005; 26: 225-232. doi:10.1055/s-2004820974

[17] Granados C, Izquierdo M, Ibanez ] et al. Differences in physical fitness and throwing velocity among elite and amateur female handball players. Int J Sports Med 2007; 28: 860-867. doi:10.1055/s-2007-964989

[18] Round JM, Jones DA, Honour JW et al. Hormonal factors in the development of differences in strength between boys and girls during adolescence: a longitudinal study. Ann Hum Biol 1999; 26: 49-62

[19] Blimkie C]. Age- and sex-associated variation in strength during childhood: Anthropometric, morphologic, neurologic, biomechanical, endocrinologic, genetic, and physical activity correlates. In: Gisolfi CV, Lamb DR., eds. Perspectives in Exercise Science and Sports Medicine: Youth, Exercise, and Sport. Indianapolis: Benchmark; 1989: 99-163

[20] Harriss DJ, MacSween A, Atkinson G. Ethical standards in sport and exercise science research: 2020 update. Int J Sports Med 2019; 40: 813-817
[21] Deutscher Handballbund. Rahmentrainingskonzeption. Dortmund: Philippka Sportverlag; 2017

[22] Tucci HT, Martins J, de Carvalo Sposito G et al. Closed kinetic chain upper extremity stability test (CKCUES test): a reliability study in persons with and without shoulder impingement syndrome. BMC Musculoskelet Disord 2014; 15: 1. doi:10.1186/1471-2474-15-1

[23] Michalsik LB, Aagaard P, Madsen K. Locomotion characteristics and match-induced impairments in physical performance in male elite team handball players. Int J Sports Med 2013; 34: 590-599. doi:10.10 55/s-0032-1329989. Epub 2012 Dec 20. PMID: 23258606

[24] Michalsik LB. On-court physical demands and physiological aspects in elite team handball. In: Laver L, Landreau P, Seil R, Popovic N., eds. Handball Sports Medicine. Heidelberg: Springer; 2018: 15-33

[25] Goldbeck T, Davies G. Test-retest reliability of the closed kinetic chain upper extremity stability test. J Sport Rehabil 2000; 9: 35-45. doi:10.1123/jsr.9.1.35

[26] De Oliveira VMA, Pitangui ACR, Nascimento VYS et al. Test-retest reliability of the closed kinetic chain upper extremity stability test (CKCUEST) in adolescents. Int J Sports Phys Ther 2017; 12: 125e132

[27] Schedler S, Brueckner D, Hagen M et al. Effects of a traditional versus an alternative strengthening exercise program on shoulder pain, function and physical performance in individuals with subacromial shoulder pain: a randomized controlled trial. Sports 2020; 8: 48. doi:10.3390/sports 8040048

[28] Bauer J, Schedler S, Fischer S et al. Relationship between upper quarter y balance test performance and throwing proficiency in adolescent Olympic handball players. BMC Sports Sci Med Rehabil 2020; $12: 1$. https:10.1186/s13102-020-00199-4

[29] Rios LJC, Cuevas-Aburto ], Martínez-García D et al. Reliability of throwing velocity during non-specific and specific handball throwing tests. Int J Sports Med 2020; 30. doi:10.1055/a-1273-8630

[30] Lagniaux F, Juin G, Rambaud AJM et al. Reference values for the closed kinetic chain upper extremity stability test for elite handball players. Int J Sports Phys Ther 2019; 14: pS10-S10

[31] Raeder C, Fernandez-Fernandez ], Ferrauti A. Effects of six weeks of medicine ball training on throwing velocity, throwing precision, and isokinetic strength of shoulder rotators in female handball players. J Strength Cond Res 2015; 29: 1904-1914. doi:10.1519/ JSC.0000000000000847

[32] Cools AM, Vanderstukken F, Vereecken F et al. Eccentric and isometric shoulder rotator cuff strength testing using a hand-held dynamometer: reference values for overhead athletes. Knee Surg Sports Traumatol Arthrosc 2016; 24: 3838-3847. doi:10.1007/s00167-0153755-9

[33] Pontaga I, Zidens ]. Shoulder rotator muscle dynamometry characteristics: side asymmetry and correlations with ball-throwing speed in adolescent handball players. J Hum Kinet 2014; 42: 41-50. doi:10.2478/ hukin-2014-0059

[34] Rousanoglou EN, Noutsos KS, Bayios IA. Playing level and playing position differences of anthropometric and physical fitness characteristics in elite junior handball players. J Sports Med Phys Fitness 2014; 54: $611-621$

[35] Edouard P, Degache F, Oullion R, Plessis JY, Gleizes-Cervera S, Calmels P. Shoulder strength imbalances as injury risk in handball. Int J Sports Med 2013; 34: 654-660. doi:10.1055/s-0032-1312587

[36] Moore SA, McKay HA, Macdonald H et al. Enhancing a somatic maturity prediction model. Med Sci Sports Exerc 2015; 47: 1755-1764. doi:10.1249/MSS.0000000000000588 